تاثير آموزش بهداشت بلوغ بر بهداشت روانى و سبك هاى هويتى دانش آموزان دختر ع - r ا ساله

مريم عزيزى'، رقيه فتحى

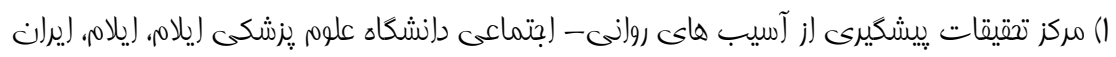

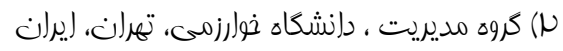

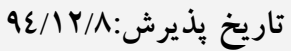
$9 \varepsilon / \varepsilon / 1 \varepsilon$

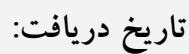

جكيده

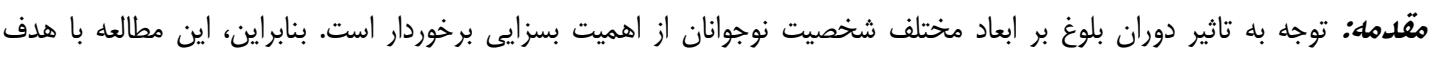

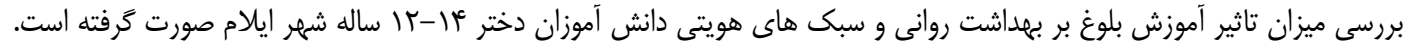

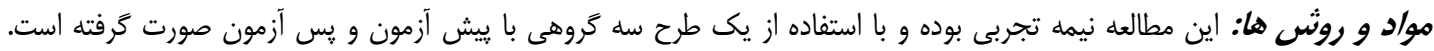

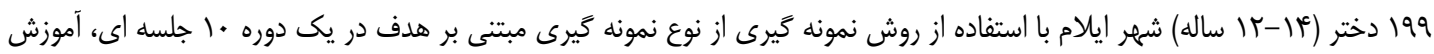

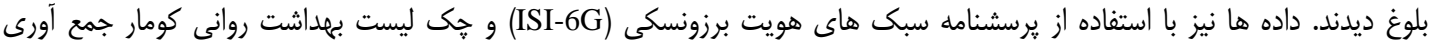
شده است.

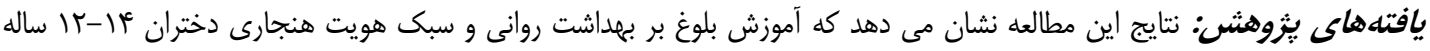

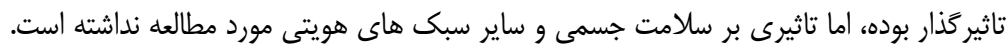

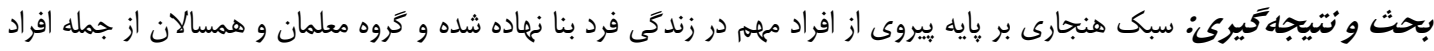

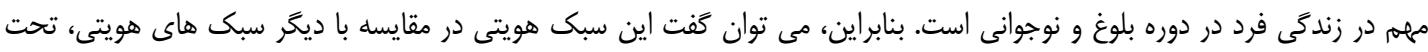

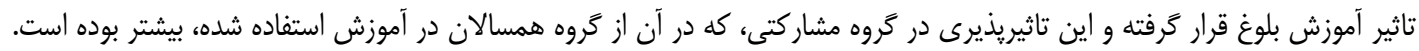

وازه هاى كليدى: آموزش بلوغ ، هويت، بهداشت روان 
هويتى را شيوه هاى شناختى - اجتماعى اتخاذ شده

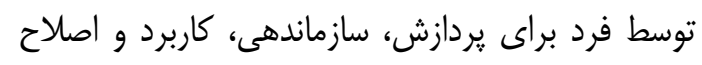

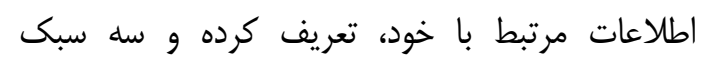
هويتى شامل سبك هاى اطلاعاتى (اطلاعات محور) ،

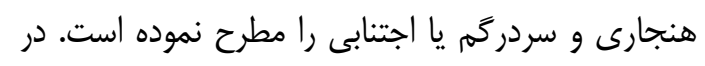

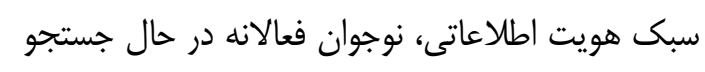

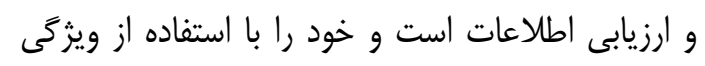

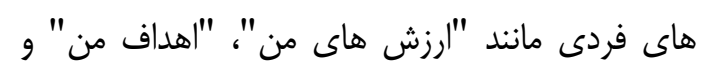

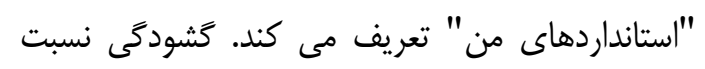

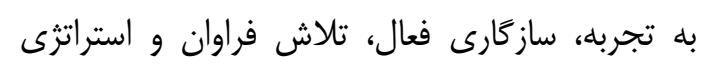

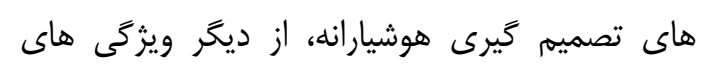

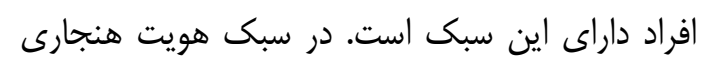

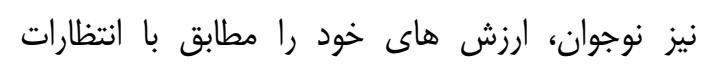

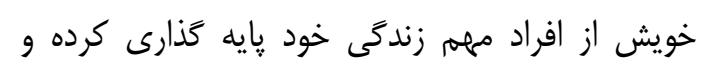

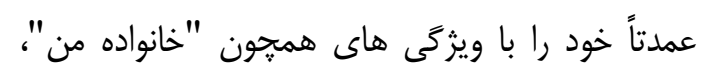

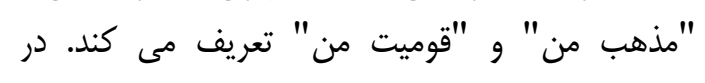

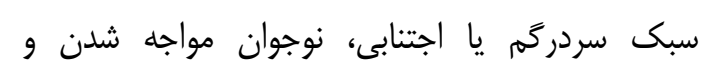

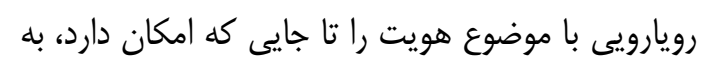

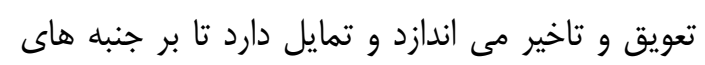

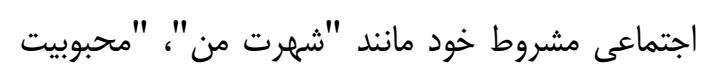

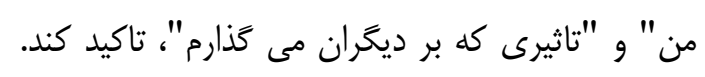
اين سه سبك هويتى، ارتباط قوى با سازكارى نوجوان

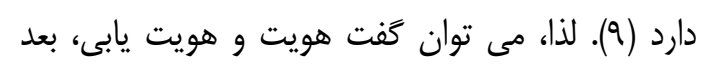

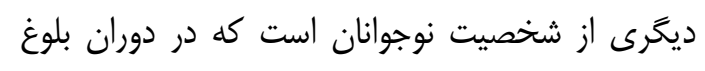

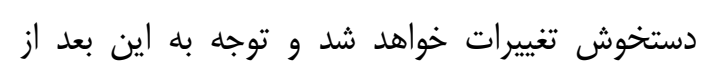

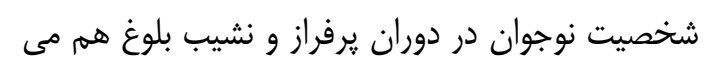
تواند جاى تأمل داشته باشد.

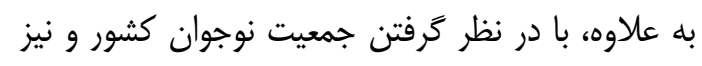

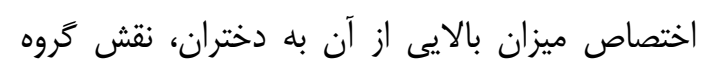

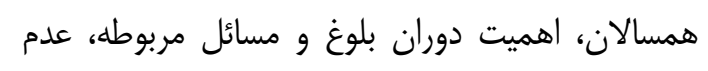

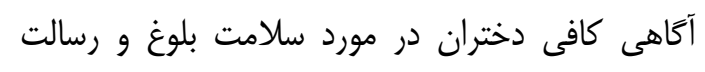

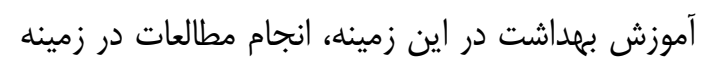
آموزش بهداشت بلوغ را ضرورى مى سازد (• (1). نتايج

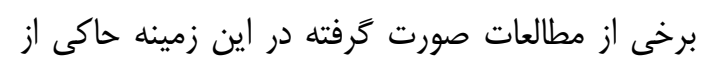

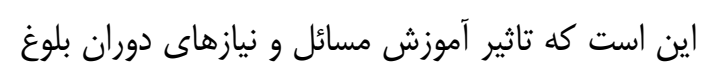

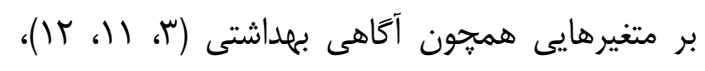

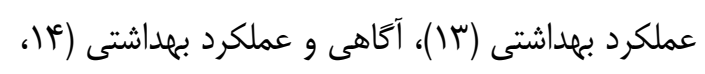

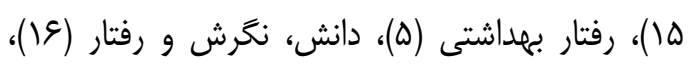

مقدمه: دوران نوجوانى در آغاز مدنيت همواره مورد توجه دانشمندان، متخصصان تعليم و تربيت و مسئولان

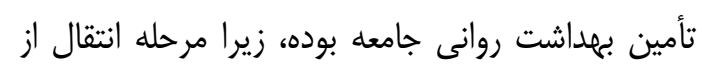
كودكى به نوجوانى و بزرگسالى، دشوارترين و طولانى رئى

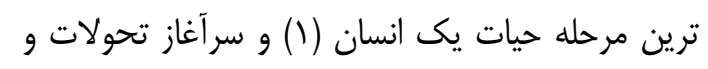

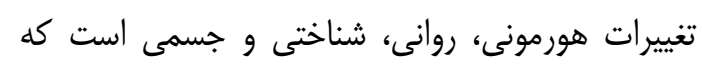

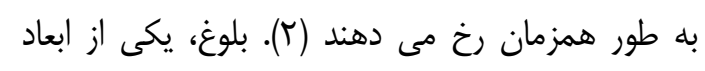

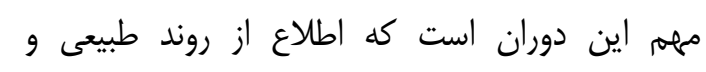

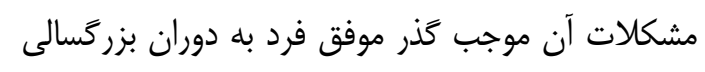

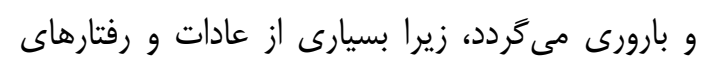

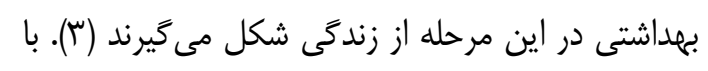

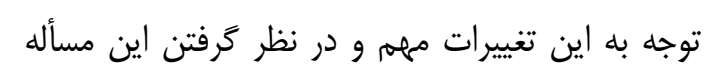
كه بخش عظيمى از جمعيت جهان را نوجوانان تشكيل

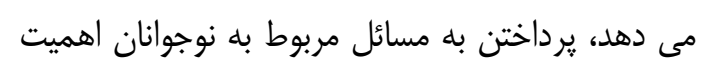

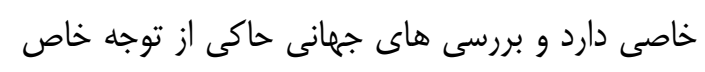

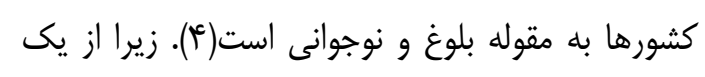

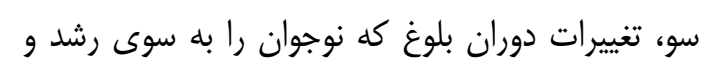
تكاملى جشمخير و عميق ييش مي برد، ارتباط بسيار

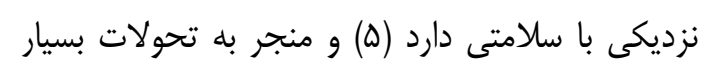

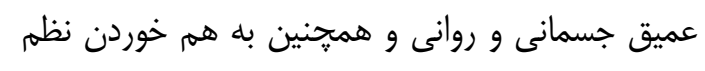

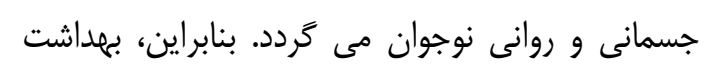
روانى و نغاه داشتن سلامت روانى نوانى نوجوانان

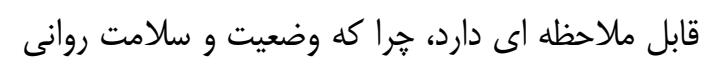

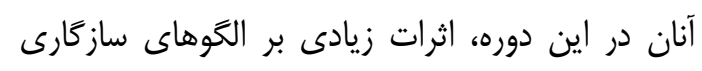
رفتارى در بزر گسالى خواهد داشت (ع). از سوى دئ ديخر،

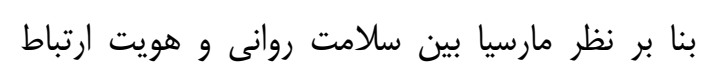

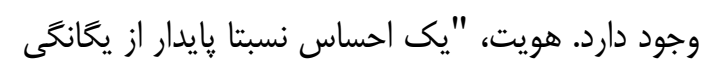

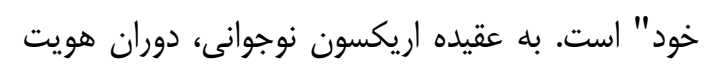

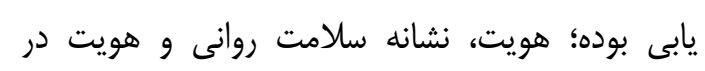

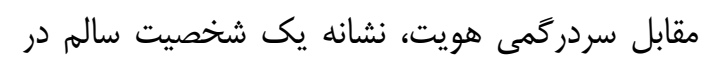

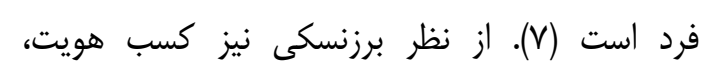

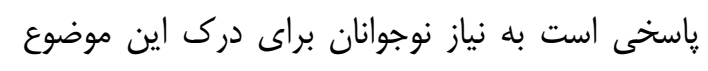

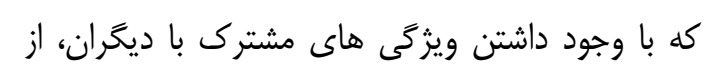

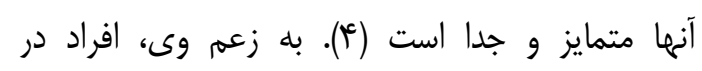
برخورد با كشمكش هاى هويتى و يردازش اطلاعات

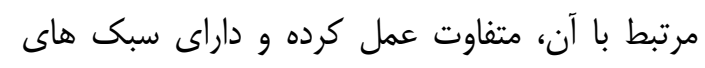

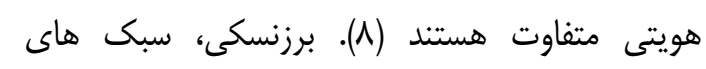


مجوز لازم از آموزش و يرورش شهرستان ايلام و هماهنگى با مديران مدارس، از مدارس متوسطه شهر

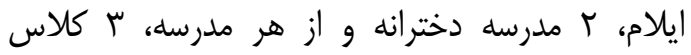

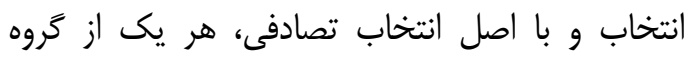

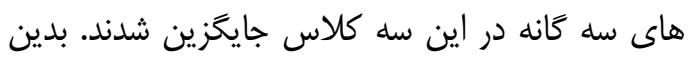

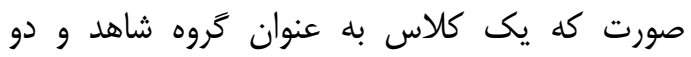

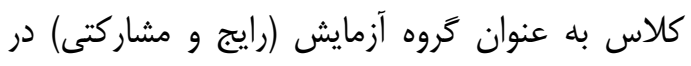

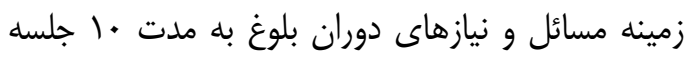
توسط يكى از معلمان سبك زندگى مدارس متوسطه،

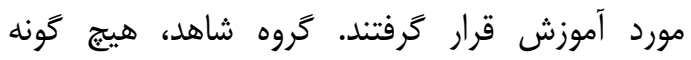

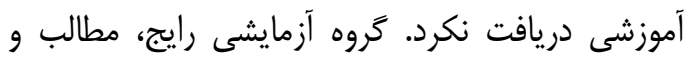

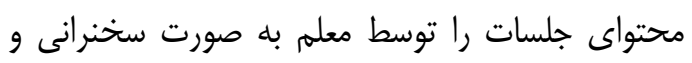

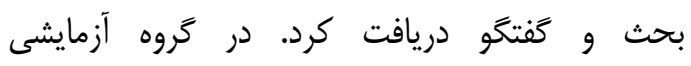

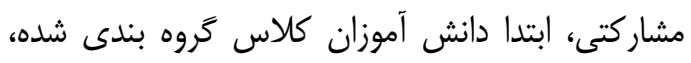

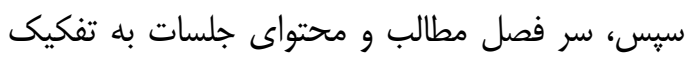

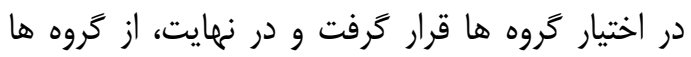
خواسته شده تا مطابق زمان بندى جلى جلسات آموزشى،

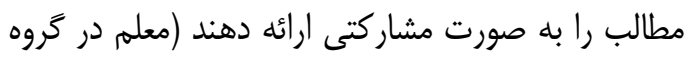
آزمايشى مشار كتى، هدايت كننده و تسهيل تر جلسات بوده است). محتواى جلسات آموزشى نيز به مارك ترتيب

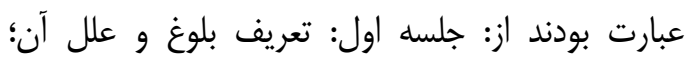

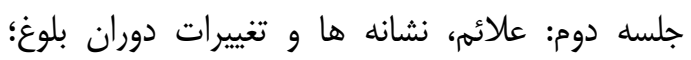

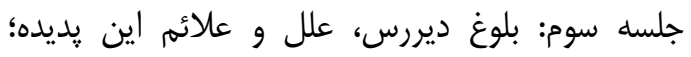

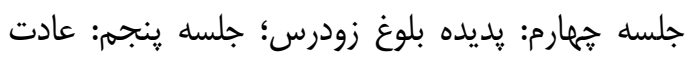

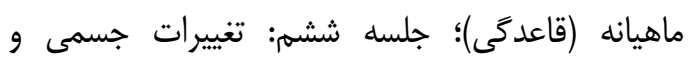

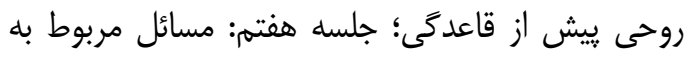

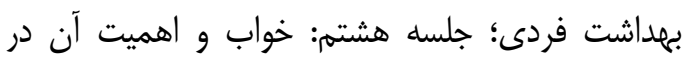

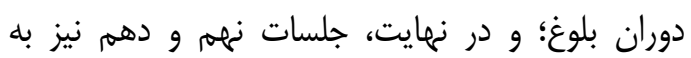

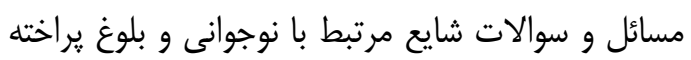

قبل و بعد از آموزش، داده هاى مورد نياز با استفاده از يرسشنامه ها جمع آورى كَرديل. ابزار جمع آورى دادي داده

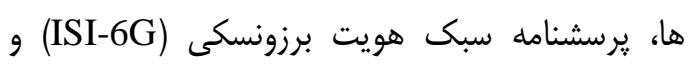

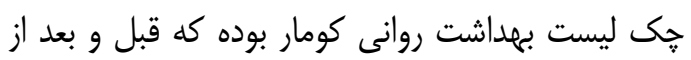

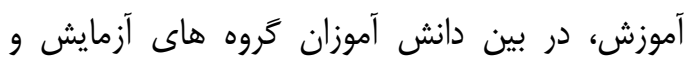

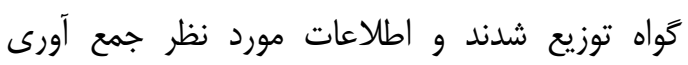

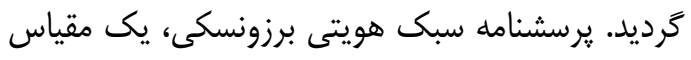

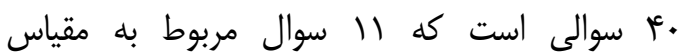

آَاهى، نخَرش و سلامت عمومى (IV)، سلامت عمومى (IV)

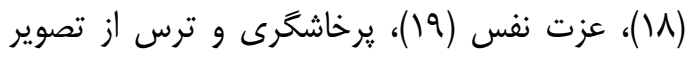

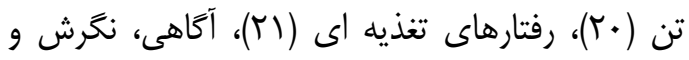

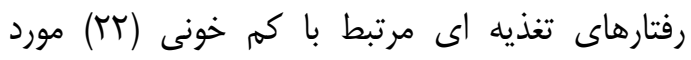

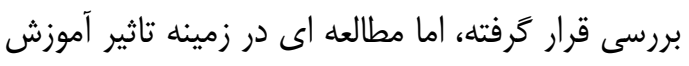

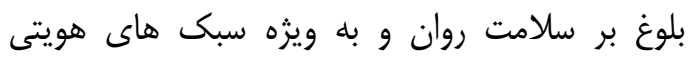

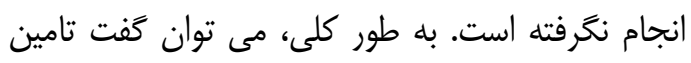

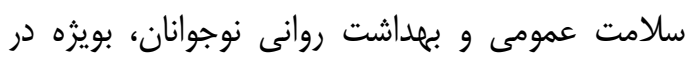

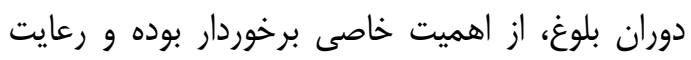
بهداشت جسم و روح كه منجر به تندرستى و شادابى إنى كامل جسمى و روحى مى شود، مهمترين وظيفه هر ورد

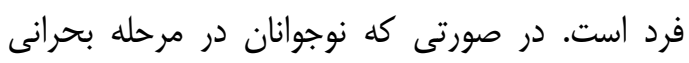

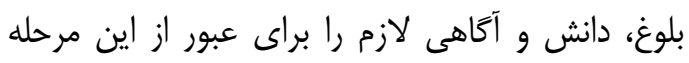

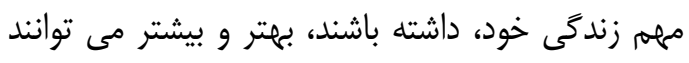

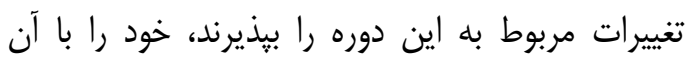

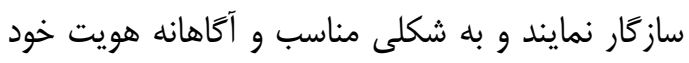

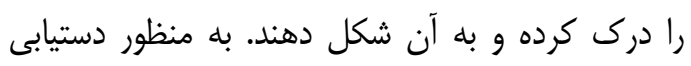
به اين هدف، يعنى بالا بردن دانش و آكاهى نوجوانان

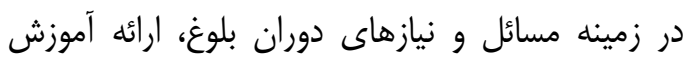

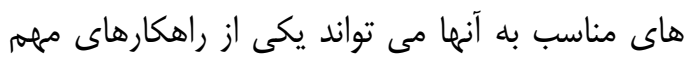

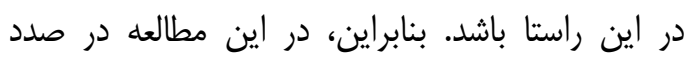

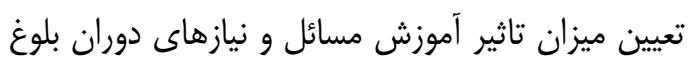
بر بهداشت روانى و سبك هويت نوجوانان بوده ايهم. به به عبارت ديغر، سوال اساسى اين مطالعه اين است كه آيا

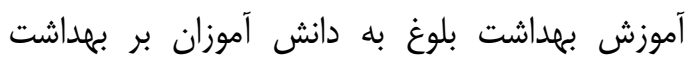

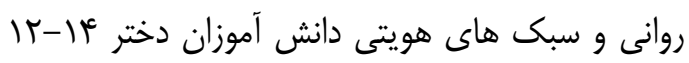
ساله تاثير كذار است ؟

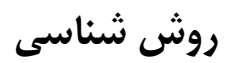
اين تحقيق از نوع نيمه تجربى بوده كه و با استفاده از

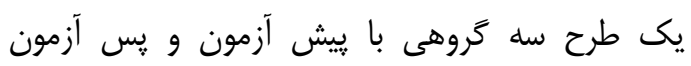

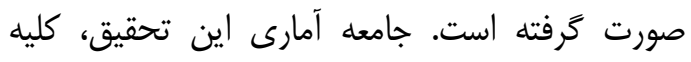

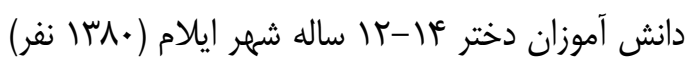
بودند كه تعداد 199 از آنها، بر اساس جداس سلدول موركان،

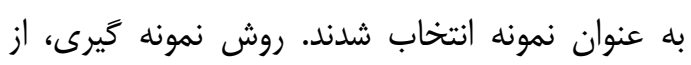

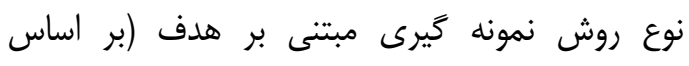

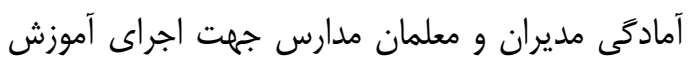

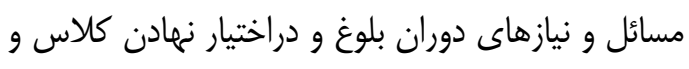

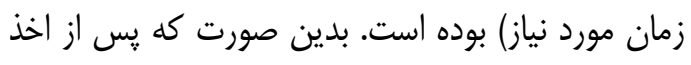


آن ها داراى مادر انى با سطح تحصيلات دييلهم بوده اند.

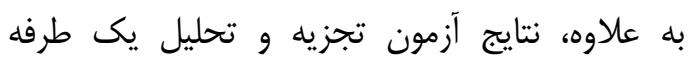

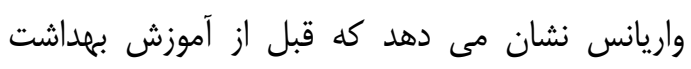

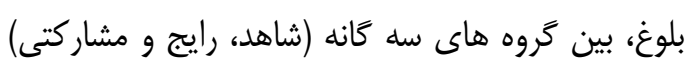

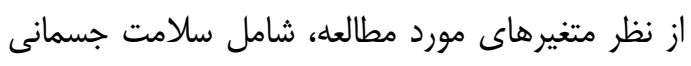

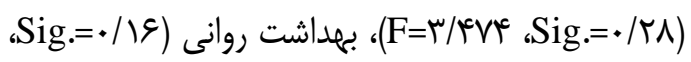

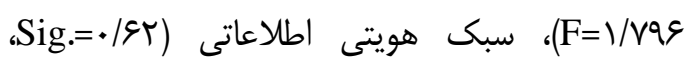

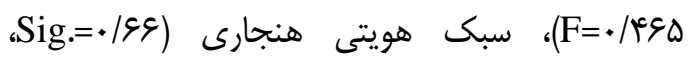

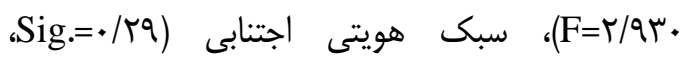
س س F=1F)، تفاوت معنادارى وجود نداشته است. به منظور بررسى اين فرض كه آيا بين سلامت متاوتان

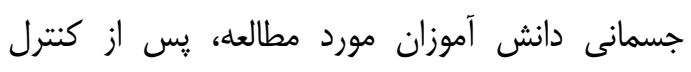

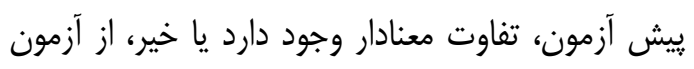
تجزيه و تحليل كوواريانس استفاده كرديد. نتايج اين

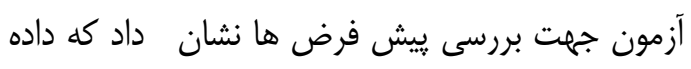

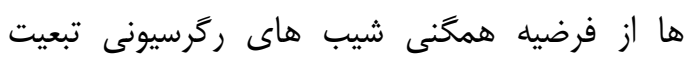

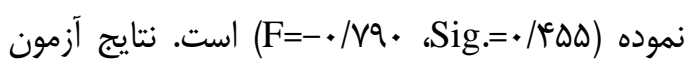

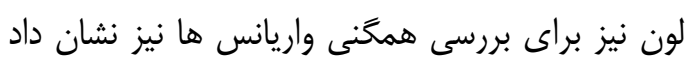
كه داده هاى مفروضه تساوى خطاى واريانس راز زير نران

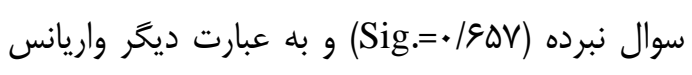

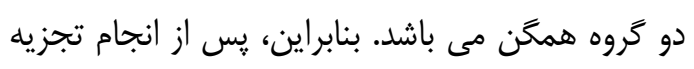

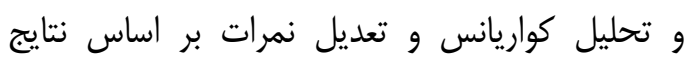

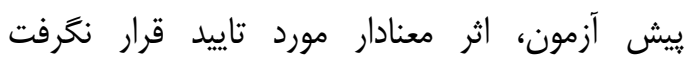

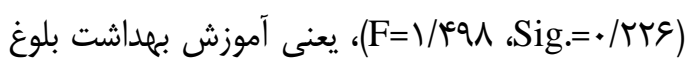

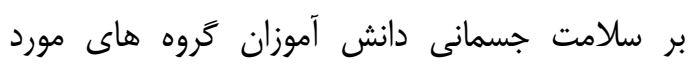
مطالعه تاثيرى نداشته است. همرجنين، نتايج آزمون

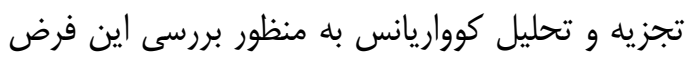

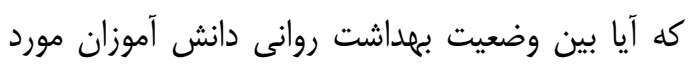

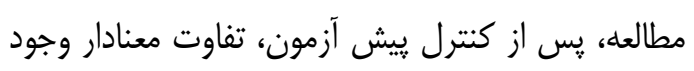

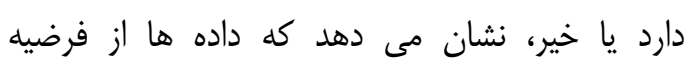

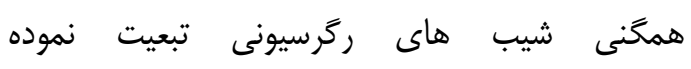

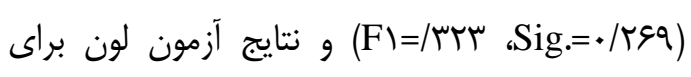

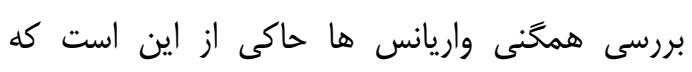

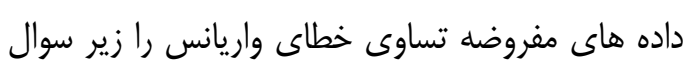

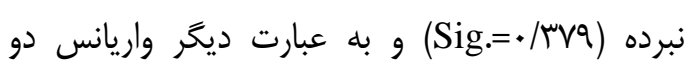
كروه همخن مى باشد.
اطلاعاتى، 9 سوال آن مربوط به مقياس هنجارى و . سوال آن مربوط به مقياس سردرگم يا اجتنابى است و و

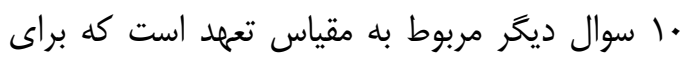

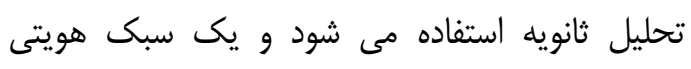

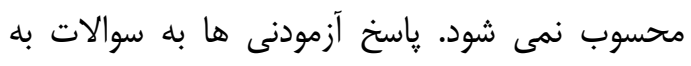

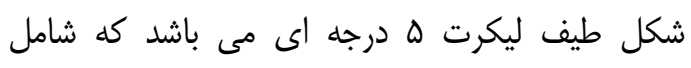

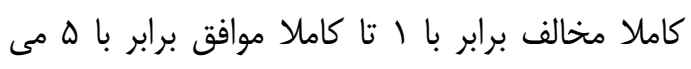

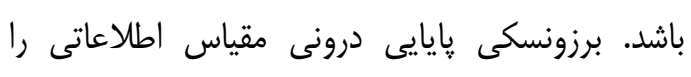

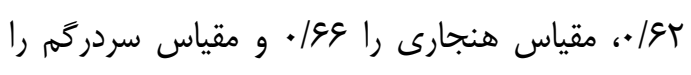

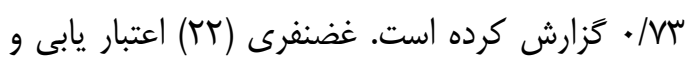

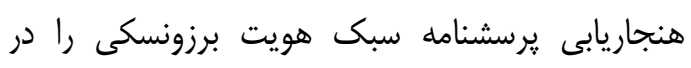

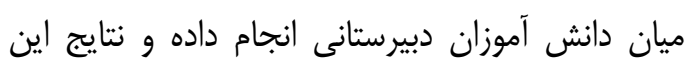

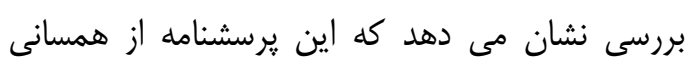
درونى مناسبى و اعتبار بالايى برخوردار است. جى ليست بهداشت روانى كومار، توسط كومار تهيه

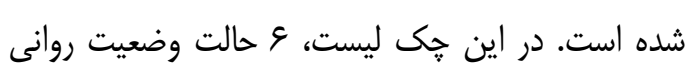

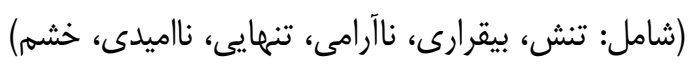

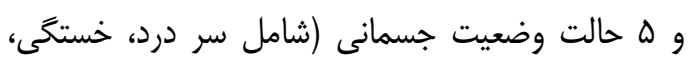
اختلال خواب، سوء هاضمه، ترش كردن) بر اساس

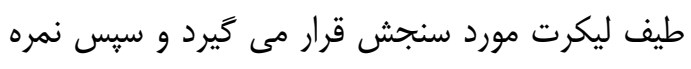

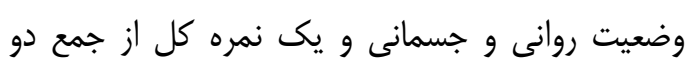

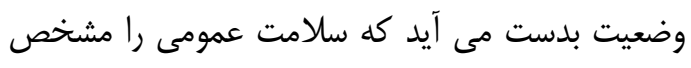

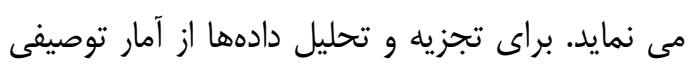

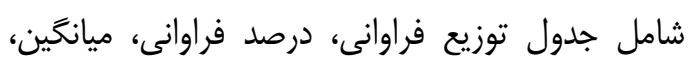

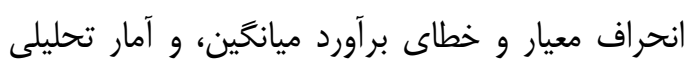
شامل آزمون تحليل كوواريانس استفاده گرديد.داده ها با استفاده نرم افزار SPSS مورد تجزيه و تحليل كرفت.

يافته هاى يزولت

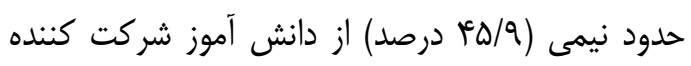

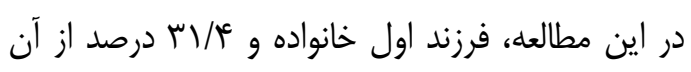

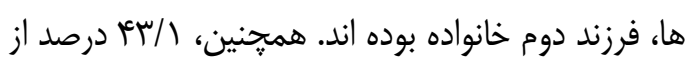

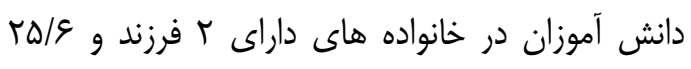

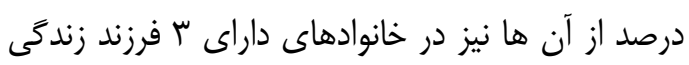

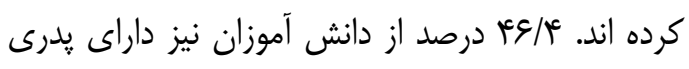

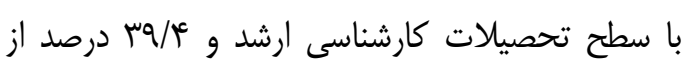

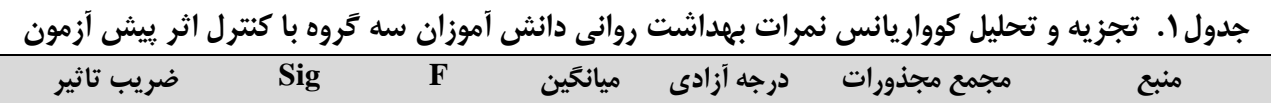




\begin{tabular}{|c|c|c|c|c|c|c|}
\hline.$/ .41$ &.$/ 111$ & $T / \cdot \pi$ & $r \backslash / \backslash \Lambda I$ & $r$ & QY/DFT & الكوى تصحيح شده \\
\hline.$/ 41$. &.$/ \cdots$ & ITr/TVq & $t \cdot k T / A T R$ & 1 & $r \cdot F r / A r V$ & مقدار ثابت \\
\hline 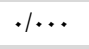 &.$/ 999$ &.$\cdots$ & I/TAF & 1 & I/TAF & ييش آزمون \\
\hline \multirow[t]{3}{*}{$+1+r+$} & $+1+\varepsilon q$ & $r / 9 \wedge \Lambda$ & $\varepsilon 0 / 1 / 0$ & $r$ & $91 / 74$. & كروه \\
\hline & & & | & 194 & rqFe/rr. & خطا \\
\hline & & & & 198 & SQ9TV/FG9 & مجموع \\
\hline
\end{tabular}

نشان مى دهد كه داده هاى مفروضه تساوى خطاى

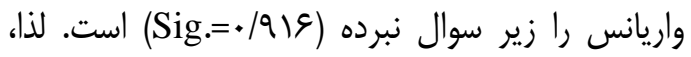
هِ از انجام تجزيه و تحليل كواريانس و تعديل نمرات

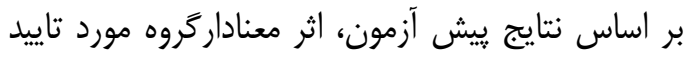

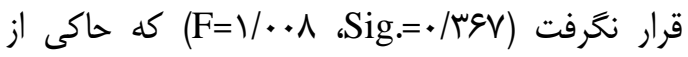
عدم تاثير آموزش بهداشت بلوغ بر بر سبك هويت اطلاعاتى دانش آموزان مورد مطالعه بوده است. به علاوه، به منظور بررسى اين فرض كه آيا بين سبك النى

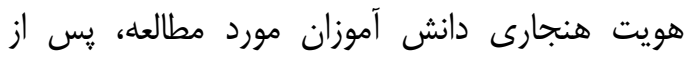
كنترل ييش آزمون، تفاوت معنادار وجود دارد يا خير، از آزمون تجزيه و تحليل كوواريانس استفاده كرديد. نتايج

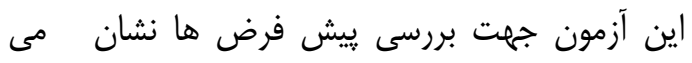

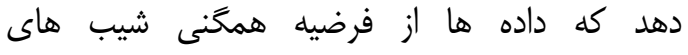

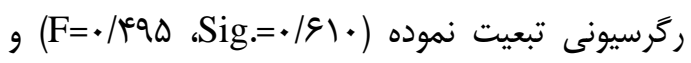

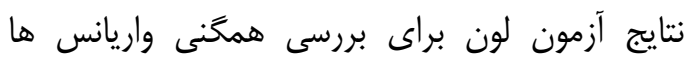
نشان داد كه داده ها مفروضه تساوى خطاى واريانس رائ لنائ

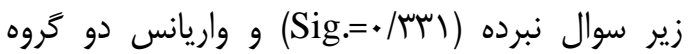
همخَ مى باشد.
بعلاوه، نتايج اين آزمون نشان دهنده اثر معنادار متغير

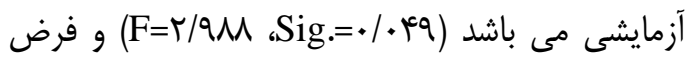
اثر آموزش بهداشت بلوغ باشد بر وضعيت بهداشت روانى

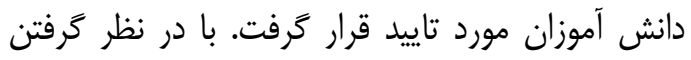

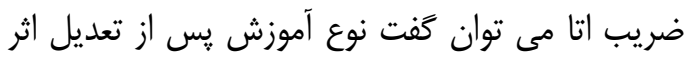

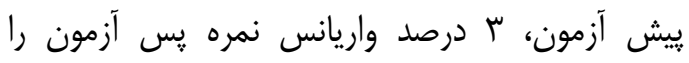

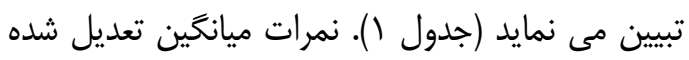
مبين اين نكته است كه كروه مشاركتى (عوعء/.

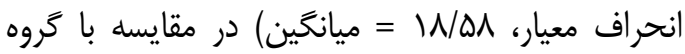

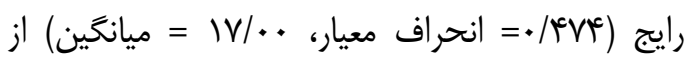
ميزان تاثيريذيرى بيشترى برخوردار بوده است. نتايج

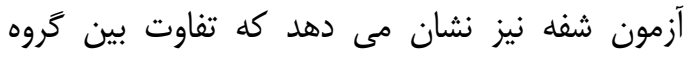

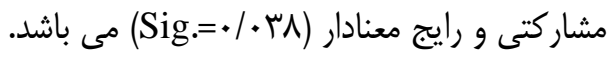

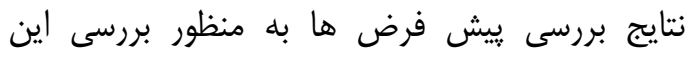
فرض كه آيا بين سبك هويت اطلاعاتى دانش آموزان

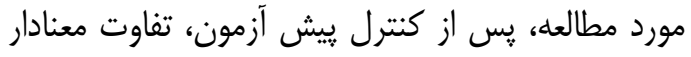

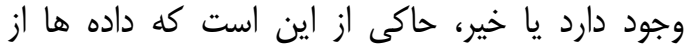

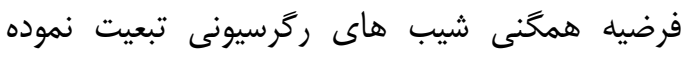

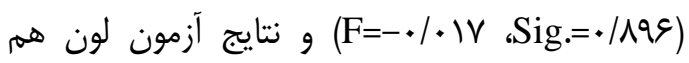

\begin{tabular}{|c|c|c|c|c|c|c|}
\hline ضريب تاثير & Sig & $\mathbf{F}$ & ميانكين & درجه آزادى & مجمع مجذورات & منبع \\
\hline.$/ . \mu$ & .1 .9$. & T/r & $91 / 9 .$. & r & $r V q / V q q$ & الكوى تصحيح شده \\
\hline.$/ 419$ & $\cdot / \cdots$ & Irr/rvq & Q.QH/IMT & 1 & Q. DH/IFT & مقدار ثابت \\
\hline . &.$/ \Delta T$. & 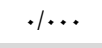 & ID/ITE & 1 & ID//KE & ييش آزمون \\
\hline \multirow[t]{3}{*}{ - } & $\bullet$ & 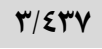 & $170 / 191$ & $r$ & ro./rq7 & كروه \\
\hline & & & rg/FTE & 195 & S994/KFE & خطا \\
\hline & & & & 198 & $r . .90 \% / \& 99$ & مجموع \\
\hline
\end{tabular}

تعديل شده مبين اين نكته است كه گروه مشاركتى

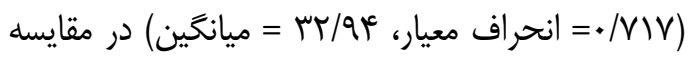

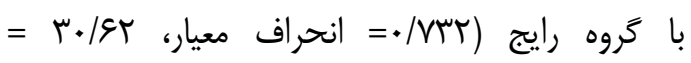

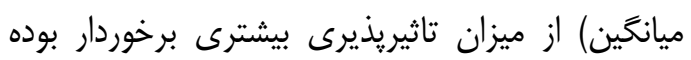

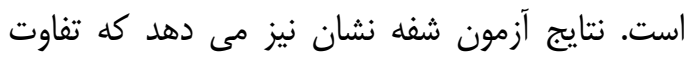

بنابراين، بر اساس نتايج حاصل از تجزيه و تحليل

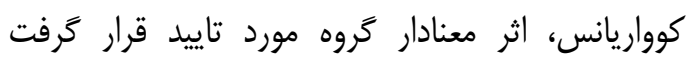

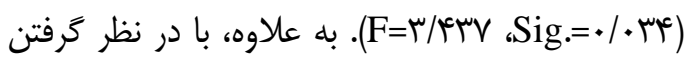

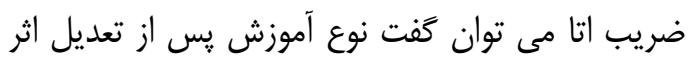

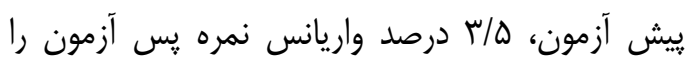

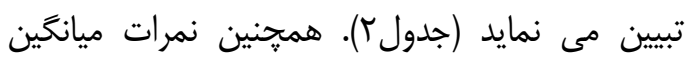




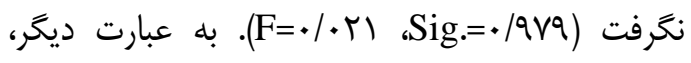

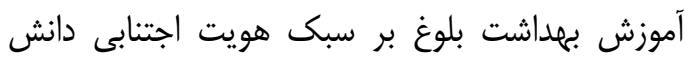
آموزان مورد مطالعه تاثيرى نداشته است.

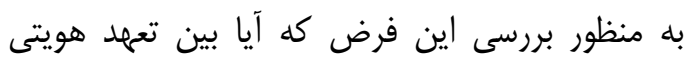

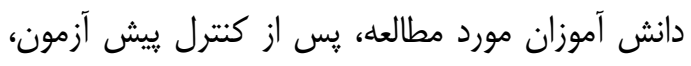

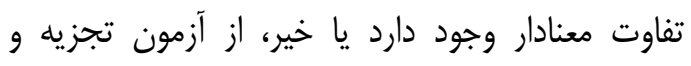

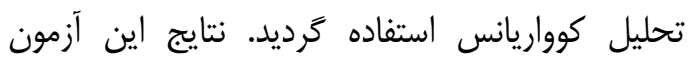
جهت بررسى ييش فرض ها نشان مى دهد كه داده ها

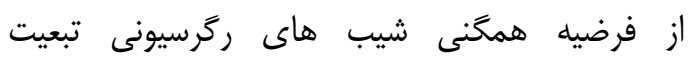

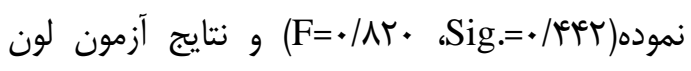

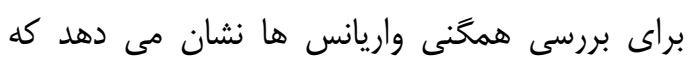

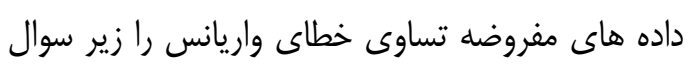

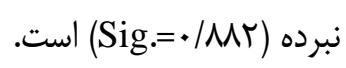

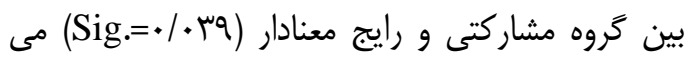
باشد. به منظور بررسى اين فرض كه آيا بين سبك هويت

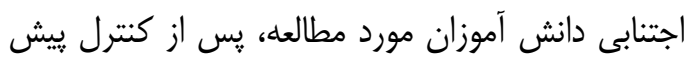
آزمون، تفاوت معنادار وجود دارد يا خير، از آزمون آزئن تجزيه و تحليل كوواريانس استفاده كَرديد. نتايج اين أزمون جهت بررسى ييش فرض ها نها نشان داد كه داده

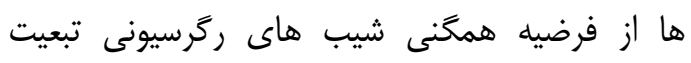

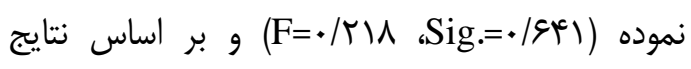
آزمون لون نيز داده ها مفروضه تساوى خطاى واريانس

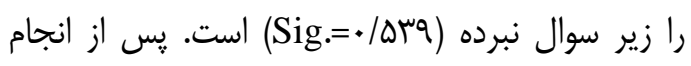
تجزيه و تحليل كواريانس و تعديل نمرات برد آنساس

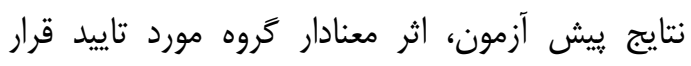
جدول r. تجزيه و تحليل كوواريانس نمرات تعهد هويتى دانش آموزان سه تروه با كنترل اثر بيش آزمون

\begin{tabular}{|c|c|c|c|c|c|c|}
\hline ضريب تاثير & Sig & $\mathbf{F}$ & ميانغَين & درجه آزادى & مجمع مجذورات & منبع \\
\hline .1 .91 & $\cdot \cdots$ & 8/99\% & $r V T / 11$. & r & 1।ร/rTq & الكَوى تصحيح شده \\
\hline . IDTA & $\cdot / \cdots$ & rIT/rg. & NFFi/g.. & 1 & NFE $1 / 9 .$. & مقدار ثابت \\
\hline . & $\cdot / 498$ & $\cdot / F \Delta S$ & $|N| l \cdot V$ & 1 & $|N| \cdot V$ & ييش آزمون \\
\hline \multirow[t]{3}{*}{+1.91} & $+1++1$ & $1+/ \varepsilon \wedge V$ & $\varepsilon+1 /+9 r$ & r & גוד/A & تروه \\
\hline & & & rN/qIF & 194 & $V \in V I / F \wedge$ & خطا \\
\hline & & & & 198 & TQQITE/TOV & مجموع \\
\hline
\end{tabular}

يوسفى و همكاران مطالعه اى با عنوان اثربخشى

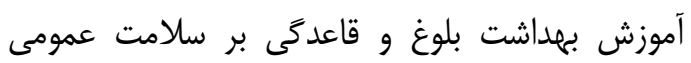

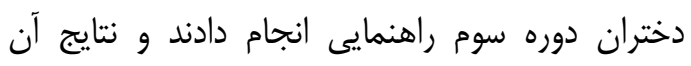

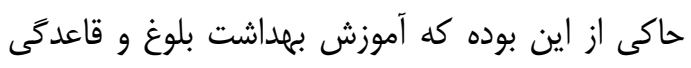

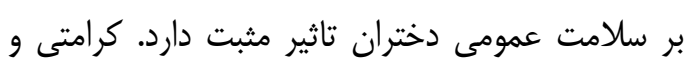

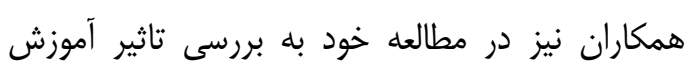

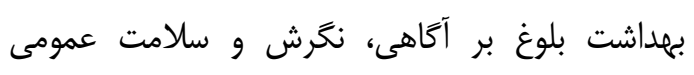
نوجوانان يرداخته و نتايج اين مطالعه بيانكر اين بوده كه بلاهن

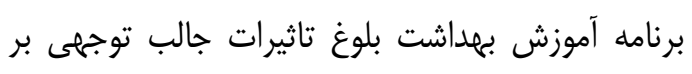

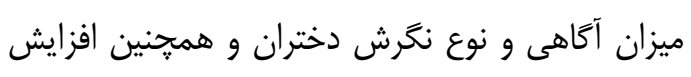
سلامت عمومى آن ها داشته است.

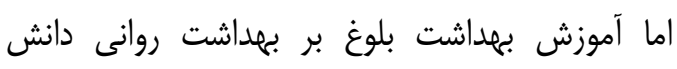

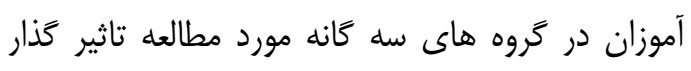

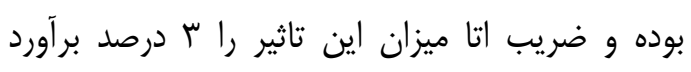

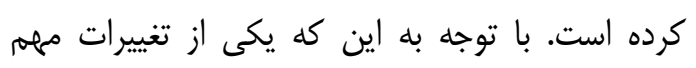

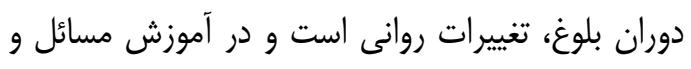
نيازهاى دوران بلوغ دانش آموزان از اين تغييرات آن دات آثاه

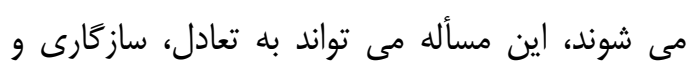

بنابراين، يس از انجام تجزيه و تحليل كواريانس و

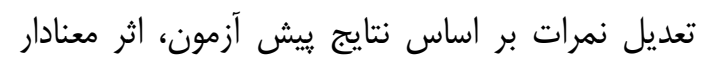

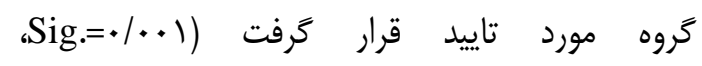
SE=1./\&AV

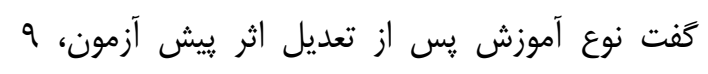

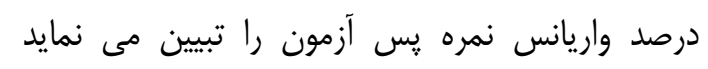

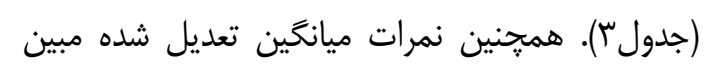

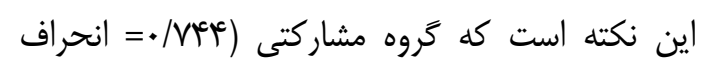

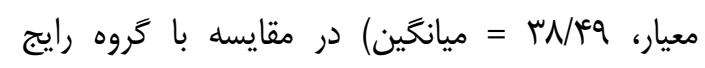

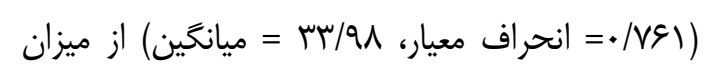
تاثيريذيرى بيشترى برخوردار بوده است. همجنين،

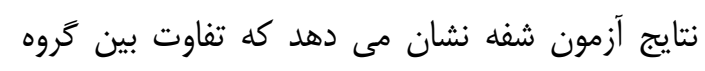

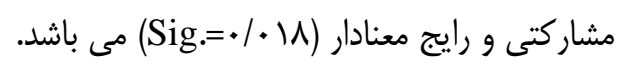
بحث و نتيجه كيرى نتايج تحليل حاكى از اين بود كه آموزش بهدئ بهاشت بلوغ

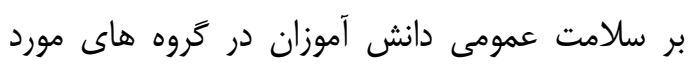

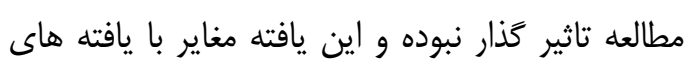
كرامتى (Y) و آقايوسفى و همكاران (IV) است. آقائ 
استفاده شده اين تاثير گذارى بيشتر بوده است. بنا به

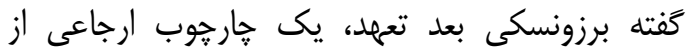

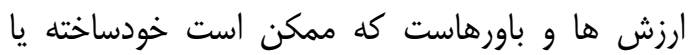

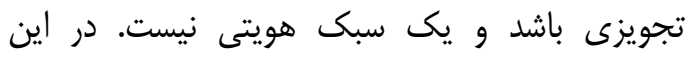

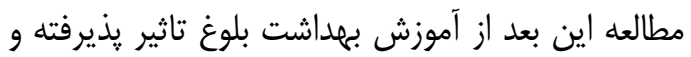
به عبارتى مى توان كفت اين جار خوب ارجاعى از باورها

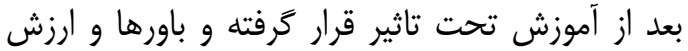
هاى فرد يس از دريافت مسائل آموزشى مورد نياز دوره تاني

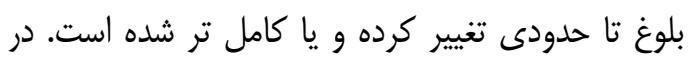
نهايت مى توان كفت دوره نوجوانى سال هاى زيادى

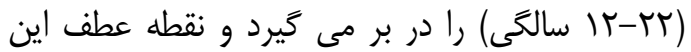

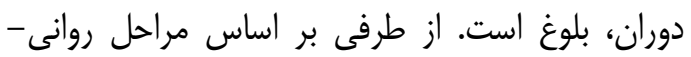
اجتماعى اريكسون، دوران نوجوانى (19-19 إن سالكى) دورانى است كه هويت فرد در آن شكل مى كي گيردا. بنابراين، همزمانى دوره بلوغ و شكل كيرى هويت در

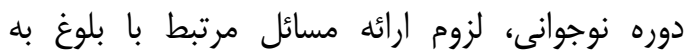

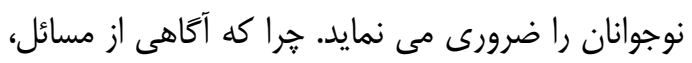
نيازها و تغييرات جسمى، روحى - روانى، ذهنى، عقلى و اجتماعى مى تواند بر هويت فرد تاثير كذار باشد. البته

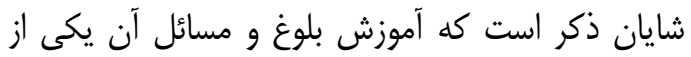

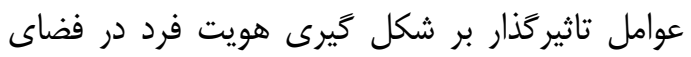
مدرسه مى باشد كه در اين مطالعه، آموزش بلوغ تاثير كمى بر سبك هاى هويتى داشته است. شايد بتوان اين نتيجه را جنين تفسير نمود كه هويت و يا كاووش و جستجو براى شكل كيرى آن در تعامل و كنش با افراد ديخر در خانواده، مدرسه و جامعه شكل مى نى گيرد و و مى تواند متاثر از عوامل متعدد ديخرى باشد كه مستلزم بررسى است.

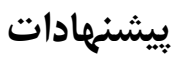

با توجه به اين كه اين مطالعه در مورد دانش آموزان

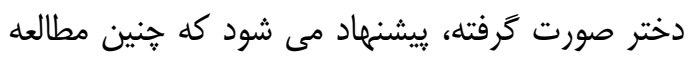
اى در مورد دانش آموزان يسر نيز صورت گيرد. با در

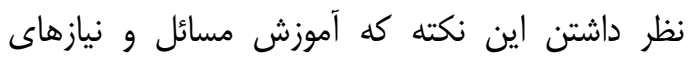

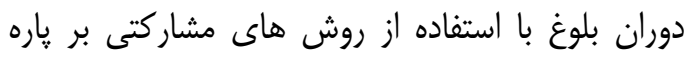
اى از متغيرهاى مورد مطالعه تاثير كذار بوده، ييشنهاد مى شود كه مطالعه اى در اين زمينه با استفاده از تكنيك هاى مختلف رويكرد مشاركتى و روش هاى

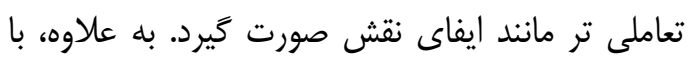

سلامت در بعد روانى كمك كند. همجنين مقايسه ميانكين كروه ها بعد از آموزش مبين اين نكته است كه كروه مشاركتى در مقايسه با كروه رايج از ميزان تاثيريذيرى بيشترى برخوردار بوده است كه مويد تأثارير روش هاى مشاركتى آموزش در مقايسه با روش رايج

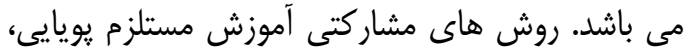
تعامل و مشاركت فعال فراگيران در فرايند آموزش بوده

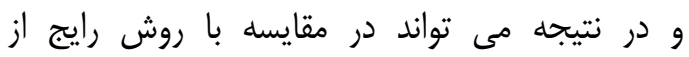
تاثير خذارى بيشترى در آموزش مسائل مختلف از جاز جمله آموزش مسائل و نيازهاى دوران بلوغ برخوردار باشد. اين بخش از يافته ها تا حدودى با نتايج مطالعه

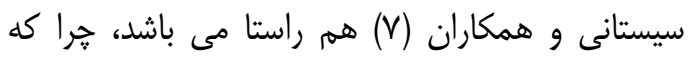

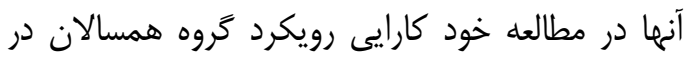
سلامت بلوغ دختران را تاييد نموده و ييشنهاد كرده اند تا آموزش هاى مربوط به سلامت بلوغ با استفاده از

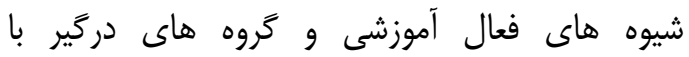

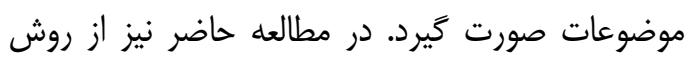
مشاركتى و همكارى و مشاركت خود دانش آموزان در آموزش بهداشت بلوغ استفاده شده و نتيجه اين كه بر مارد بهداشت روانى آن ها در مقايسه با روش بل رايج تاثير كذارتر بوده است. به علاوه، نتايج تحليل داده ها در زمينه آموزش بهداشت بلوغ بر سبك هاى هويتى دانش آموزن در

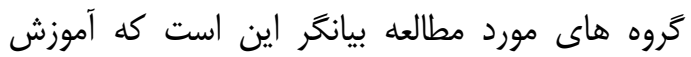

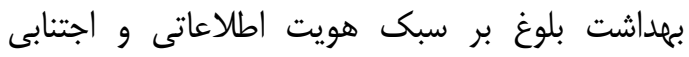
تاثيرى نداشته است. اما اين آموزش بر سبك هويت هنجارى و تعهد هويت تاثير گذار بوده و ضريب اتا

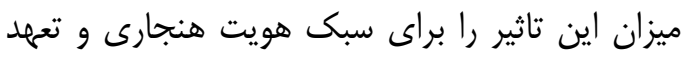

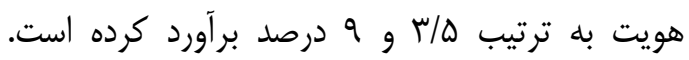
همجنين، نتايج مبين اين نكته است كه گروه مشاركتى در مقايسه با گروه رايج از ميزان تاثيريذيرى بيشترى

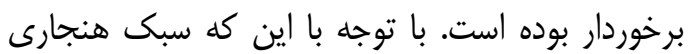

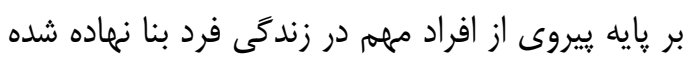

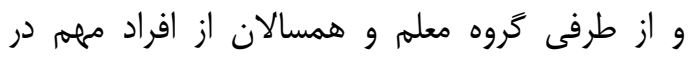
زندگى فرد در دوره بلوغ و نوجوانى است، مى توان كفت اين سبك در مقايسه با دو سبك دئ ديخر، تحت

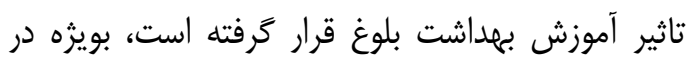
كروه مشاركتى كه در امر آموزش از كروه همسالان 


$$
\begin{aligned}
& \text { مطالعه اى در اين زمينه با استفاده از روش هاى نمونه } \\
& \text { كيرى تصادفى صورت گيرد. } \\
& \text { سياسگزارى } \\
& \text { اين مقاله حاصل طرح يزوهشى مصوب در مركز }
\end{aligned}
$$

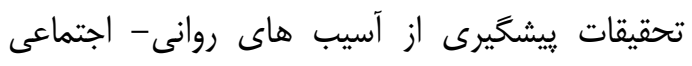

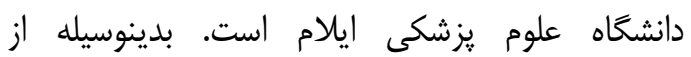

$$
\begin{aligned}
& \text { همكارى صميمانه مركز تحقيقات به خاطر حمايت مالى دئل }
\end{aligned}
$$

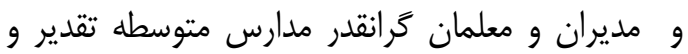

$$
\begin{aligned}
& \text { تشكر مى شود. }
\end{aligned}
$$

$$
\begin{aligned}
& \text { توجه به اين كه آكَاهى از تغييرات دوران بلوغ از طريق } \\
& \text { منابع سالم و معتبر، سلامت روانى قشر هدف را بدنبال }
\end{aligned}
$$

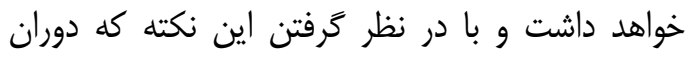

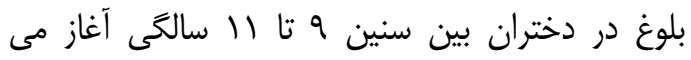

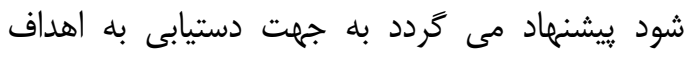

$$
\begin{aligned}
& \text { مورد نظر و جلوكيرى از كسب اطلاعات از منابع } \\
& \text { نامعتبر، اين آموزش در سال هاى پايانى دوران ابتدايى إنى }
\end{aligned}
$$

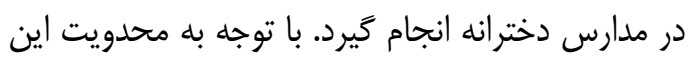

$$
\begin{aligned}
& \text { مطالعه در زمينه تعميم نتايج، به علت استفاده از روش مان } \\
& \text { نمونه كيرى مبتنى بر هدف، بيشنهاد مى شود كه }
\end{aligned}
$$

\section{References:}

1.Ahadi H, Mohseni, N. Growth psychology basic conceptions in adolescent and adulthood psychology. $10^{\text {th }}$ ed. Tehran Bonyad publication. 2002; P.288-15. (Persian)

2.Ha JY, Kim SH, Choi HY, Ahn YM. Early Puberty is associated with psychological health problems in Korean adolescents. Adv Sci Technol Let 2015;103:227-31.

3.Khakbazan Z, Jamshidi F, Mehran A, Damghanian M. [The comparison of two training educating method presentation-learning box on the female conscious about maturity health]. $J$

Nurs Obstet Acad Tehran Med Sci Uni 2008; 14: 41-8. (Persian)

4.Alaviseyed S, Hashemyan K, Janatifard F. [The comparison of identity and mental health in students that use the internet and the virtual environment of Tehran's University]. J Behavior Sci 2008;6:27-35. (Persian)

5.Taghdisi MH, Noorisistani M, Marghaiekhoie AA, Husseini F, Asgharnejadfarid AA. [Survey the effect of coeval's group on the teen girls function and conscious in the term of mental health]. J Yazds Health Acad2011;3:92-105. (Persian)

6.Abdizarin, S, Aghayosefi A, GhaedAmini Gh, Mohammadi E, Khali A. [Identical styles relation adolescent mental health and depression and education success in the Qoms male high schools]. J Birjands Islam Azad Uni2009;21:119-34. (Persian)

7.Noorisistani M, Marghaiekhoie A. [The effect of educating based upon the coevals method on the girls maturity physical health]. J Arak Med Sci Uni 2009;12:129-35. (Persian)

8.Soenens B, Berzonsky M, Papini D. Attending to the role of identity exploration in selfesteem longitudinal associations between identity styles and two features of self esteem. Int $\mathbf{J}$ Behavior Dev 2016; 40: 420-30.

9.Crocetti E, Erentait R, Zukauskien R. Identity styles positive youth development, and civic engagement in adolescence. J Youth Adol 2014;43:1818-28.

10.Shirzadi SH, Shojaiezade D, Taghdisi MH, Hassani A, Doshmangir P. [Survey the effect of training through group discussion on the teen girls physical maturity health conscious that settle in the Tehrans hostelry welfare center]. J Yazd Health Acad 2013;12:164-77. (Persian)

11.Moedi M, Zamanipour N, Sharifzade GH, Akbariborang M, Salehi S. [The evaluation of adolescent health training plan in the Birjands junior and secondary students conscious]. $\mathrm{J}$ Birjand Med Sci Uni2006;13:36-41. (Persian)

12.Hezavei SMM, Taghdisi MH, Mahthhakak H, Hassanzade A. [The effect of three training method consist of presentation game and playing role on the female guidance students conscious and function about the nutrition of adolescent maturity]. J Dev Step Med Edu2006;3:126-33. (Persian)

13.Jalili Z, Mohammadalizade S, Ataolahi S. [Survey the effect of health training on the junior guidance female students conscious and function on Babel in the terms of menstrual health]. $\mathrm{J}$ Dev Step Med Edu2004;1:41-7. (Persian)

14.Zabihi, A. [Survey the effect of training on the conscious level and female students function in the relation with adolescent maturity health]. J Babol Med Sci Uni2002;3:58-62. (Persian) 
15.Afghari A, Eghtedari S, Pashmi R, Sadri GH. [Effects of puberty health education on 10-14 year-old girls' knowledge, attitude, and behavior]. Iranian J Nurs Midwife Res 2008; 13: 38-41. 16.Keramati M, Esfandiari M, MahjobeshratAbadi H. [The effect of maturity health training on consciousness the attitude toward teenagers general health]. J New Train Thought 2009; 5:3550. (Persian)

17.Aghayosefi A, Alipour A, Najarihassanzad F. [The effectiveness of maturity health and menstrual education on the general health of junior guidance]. J Psychol Stud2009;3:105-18. (Persian)

18.Makari H, Kheirkhah M, Neysani samani L, Hassani AF. [The effect of adolescent training on the teenager's confidence]. J Nurs Res 2013; 8: 47-57. (Persian)

19. Ataie Moghalo V, Basaknejad S, Mehrabizade Honarmand M, Ataie Moghalo R, Ataie Moghalo S. [The effect mental maturity health on the aggressiveness and fear of students body image in the second year of secondary of Ahvaz]. J Health Safety 2014; 5:138-48. (Persian)

20.Nazari, M, Niknami SH, Heydarnia A, Babaie Gh, Ghahramani L. [Survey the level of health training effect on the trophic behaviors of primary female schools]. J Shahed Med Uni2005;13: 65-70. (Persian)

21.Shahnazi H, Tabaresfahani M, Azarbin S, Hassanzade A, Chargazi A, Moedi M. [The effect of health training plan based upon PRECEDE pattern on the attitude and trophic behaviors consciousness related to the anemia in the Secondary female students of Esfahan]. $J$ Health Sys Stud2012; 8:773-81. (Persian)

22.Ghazanfari A. [Credibility and normalizing the identical style questionnaire (ISI-G6)]. J Train Psychol Stud Ferdosi Uni Mashhad 2004;17: 81-94. (Persian) 


\title{
The Effect of Puberty Health Education on 12-14 Year-Old Girls' Mental Health and Identity Styles
}

\author{
athi $R^{I^{*}}, A z i z i M^{2 *}$
}

(Received: July 5, 2015 Accepted: February 27, 2016)

\begin{abstract}
Introduction: Paying attention to puberty periods effects on different dimensions of adolescents' personality has an essential importance. Therefore, this study aimed to determine the effect of puberty health education on 12-14 year-old girls' mental health and identity styles.

Materials \& methods : In this semiexperimental study using three groups with pre-test and post-test, 199 girls (10-14 yearold) were selected from schools in Ilam city using purposeful sampling and were educated in a ten-session course. Data were collected using Bersonsky Identity Style Questionnaire and Kumar Mental Health Check List.
\end{abstract}

Findings: The results of this study showed that puberty health education has an effect on mental health and normal identity style of 12-14 year-old girls', but has no effect on their physical health and other identity styles.

Discussion \& conclusions: Normal identity style was created by following important people's life; furthermore, teachers and peers groups are important people in the life of each person in adolescence and puberty periods. Therefore, it can be said that this identity style was affected by puberty health education in comparison with other identity styles; this effect has been more in cooperative group that we used peers group education.

Keywords: Puberty health education, Identity, Mental health

1. Dept of Management, Kharazmi University, Tehran, Iran

2. Research Center of Prevention of Psychosocial and Social Impairments, Ilam University of Medical Sciences, Ilam, Iran

*Corresponding author E-mail: frogh82@gmail.com 